\title{
Approach to the Adolescent With Substance Use in the Acute Setting
}

\author{
Sujetha Sathanantham ${ }^{1}$, Kavinda Dayasiri ${ }^{2}$, Vijayakumary Thadchanamoorthy ${ }^{3}$ \\ 1. Preliminary Care Unit, Lady Ridgeway Hospital, Colombo, LKA 2. Paediatrics, Faculty of Medicine, University of \\ Kelaniya, Ragama, LKA 3. Clinical Sciences, Faculty of Health Care Sciences, Eastern University, Batticaloa, LKA
}

Corresponding author: Kavinda Dayasiri, kavindadayasiri@gmail.com

\begin{abstract}
Psychoactive substance use during adolescence is an emerging challenge to the public health system due to the potential negative impact on the emotional, cognitive, social, physical and academic outcomes of adolescents. An increase in autonomy during adolescence, peer influence and willingness to experiment, lead to taking high-risk decisions subsequently prompting towards substance abuse and alcohol use. Substance use is heterogeneous among adolescents, which differs with availability, perceptions of use and specific drug usage. In adolescents' substance abuse, beyond emergency care, brief counselling with psychosocial assessment and follow up are recommended for successful management.
\end{abstract}

The article reviews the common substances used by adolescents, types of presentations, clinical evaluation of patients and their background, laboratory testing, emergency management and follow up for long-term management.

Categories: Emergency Medicine, Pediatrics

Keywords: substance, adolescent, intoxication, supportive care, mental health

\section{Introduction And Background}

Adolescence is defined by the World Health Organization (WHO) as "the transition period from childhood to adulthood ranging from ages 10 to 20 years." Adolescents contribute to $16.1 \%$ of the total population of Sri Lanka and approximately, 70\% of them attend school [1]. According to a survey conducted in Sri Lanka in 2016, 2.7\% of schooling students consume addictive substances [1]. Adolescence is a most challenging developmental period, especially consisting of biological, psychological, social and cognitive development. Further, peer pressure and greater autonomy from parents contribute to risk-taking behaviour and exploration, which are major factors for adolescents' substance abuse [2]. The commonly consumed substances during this period are cannabis, stimulants, opioids and hallucinogens. Moreover, adolescents have a high risk of experiencing several negative consequences, such as non-fatal and fatal injuries, academic failure, violence, addiction, suicidal attempts, sexually transmitted infections and unintended pregnancy, due to substance consumption [2].

Review began 06/12/2021 Review ended 06/30/2021 Published 07/11/2021

\section{(๑) Copyright 2021}

Sathanantham et al. This is an open access article distributed under the terms of the Creative Commons Attribution License CC-BY 4.0., which permits unrestricted use, distribution, and reproduction in any medium, provided the original author and source are credited.
While encountering adolescents with suspicion for substance abuse in an emergency setting, physicians have to elicit detailed history and physical examination to discover specific toxidromes such as anxiety with intractable nausea and vomiting in cannabis intoxication and respiratory depression and miosis in opioid intoxication. However, the manifestations of substance use extend beyond specific toxidromes mainly due to poly-drug usage [3]. A timely and efficient therapeutic approach is essential in an emergency setting because rapid clinical deterioration can lead to life-threatening complications.

\section{Review \\ Clinical presentation}

Adolescents have limited insight regarding the threats of substance consumption. Acute unpleasant symptoms or medical complications following consumption lead to emergency care visits. However, some people present with suicidal attempts, mental health disorders such as anxiety disorders, psychotic disorders, and mood disorders, and participate in risky behaviour such as driving under the influence of substances or engaging in sexual activities [3].

\section{Evaluation in an acute setting}

Adolescents with substance abuse are usually brought to the emergency department by concerned family members. Obtaining collateral information from family members or other sources will assist in clinical evaluation. Maintaining a non-judgmental, open-minded approach towards adolescents and accompanying family members facilitates the acquisition of accurate information and helps to better understand adolescent's circumstances. Careful history taking and focused examination help in risk assessment and management (Table 1) [3]. 


\section{Cureus}

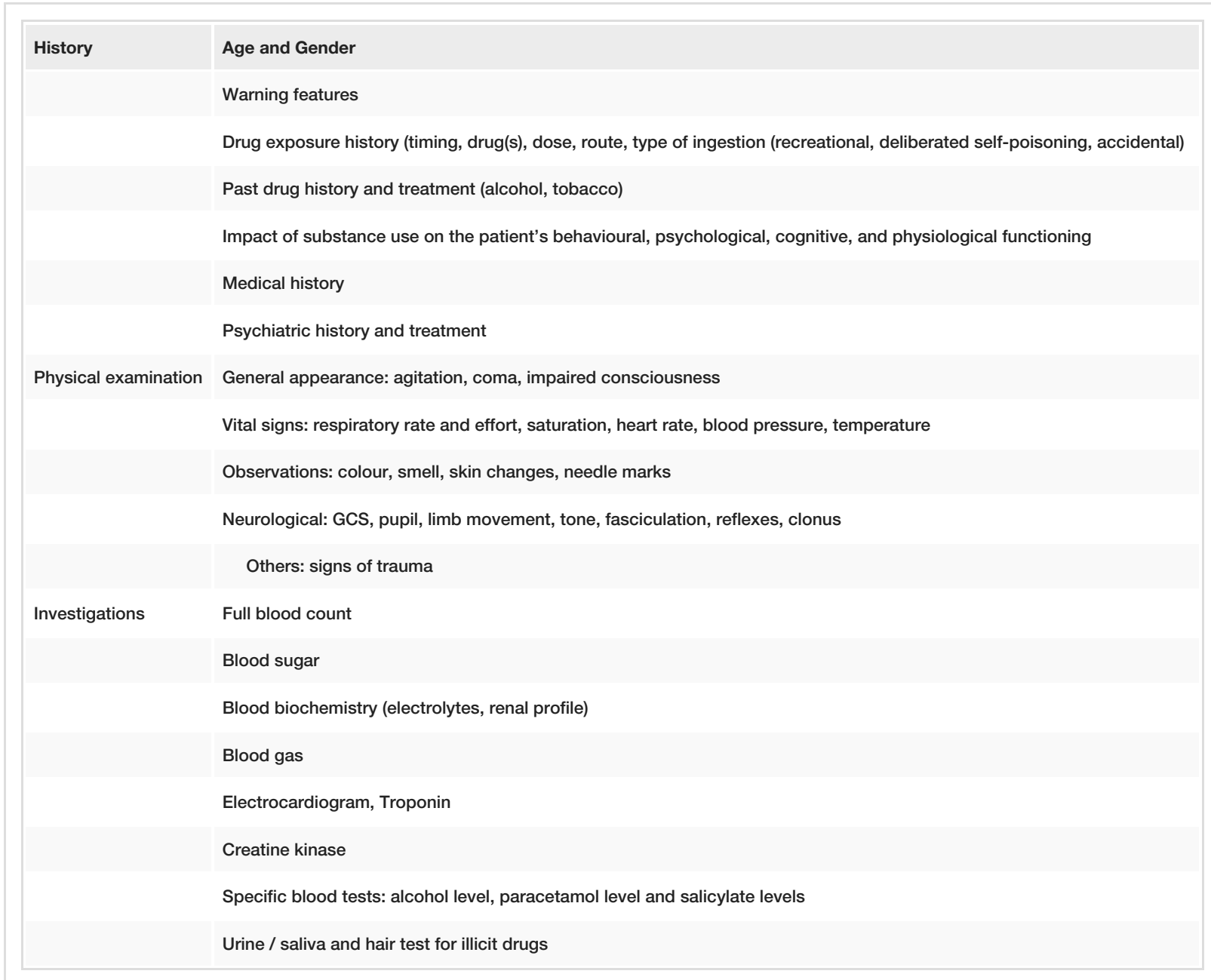

TABLE 1: Initial assessment of suspected substance overdose

The managing clinician should be aware that adolescents are a high-risk population for multiple substance ingestion. Therefore, it is essential to gather comprehensive history, including details of substance use such as alcohol, caffeine, tobacco, over-the-counter medications, herbal preparations and prescription medication. The history of pre-existing medical conditions is important for the effective management and excluding other organic pathologies. Mental health assessment is crucial to differentiate pre-existing psychiatric illness or mental illness linked with substances and to assist subsequent psychiatric referral $[3,4]$.

Illicit substance users often use multiple terminologies. Table 2 contains common street names for substances and the routes of administration that may aid conversation with patients $[4,5]$. 


\section{Cureus}

\begin{tabular}{|c|c|c|c|}
\hline Drug name & Street name & Route & Duration of effect \\
\hline Cannabis & Marijuana, Ganja, Weed, Pot, Grass, Hash, Joint, Mull, Dope, Cone & Smoked, oral & $1-3 \mathrm{~h}$ \\
\hline $\begin{array}{l}\text { Amphetamines } \\
\text { (methamphetamine, } \\
\text { PMA) }\end{array}$ & Speed, Meth, Ice, Jib crystal, Uppers, Tina & $\begin{array}{l}\text { Oral, snorted, smoked, } \\
\text { injected (IM) }\end{array}$ & $\begin{array}{l}6-8 \mathrm{~h} \text { if taken orally or } \\
\text { injected, } 10-12 \mathrm{~h} \text { if } \\
\text { smoked }\end{array}$ \\
\hline Cocaine & Snow, Crack, Coke, Rock, C, Flake, Candy, Charlie & $\begin{array}{l}\text { Snorted, injected (IV), } \\
\text { smoked (crack) }\end{array}$ & $10 \mathrm{~min}$ if smoked \\
\hline Ecstasy (MDMA) & XTC Eccies, M\&Ms, E, X, Adam, Hug drug & Oral, snorted & $\begin{array}{l}\text { 4-6 } \mathrm{h} \text { (dependent on } \\
\text { dose) }\end{array}$ \\
\hline Heroin & $\begin{array}{l}\text { Smack, Horse, Junk, Ska, Brown, Harry, “H”, Speedball (injected } \\
\text { with cocaine) }\end{array}$ & $\begin{array}{l}\text { Smoked, injected (SC, } \\
\text { IM, IV), snorted, oral } \\
\text { (pills) }\end{array}$ & $3-5 \mathrm{~h}$ \\
\hline $\begin{array}{l}\text { V-hydroxybutyrate } \\
\text { (GHB) }\end{array}$ & $\begin{array}{l}\text { Fantasy, Liquid G, Date rape drug, Gina, Grievous bodily harm, } \\
\text { Cherry meth, Liquid Fanta, Easy Lay, Georgia Homeboy, Liquid } \\
\text { Ecstasy }\end{array}$ & Oral, snorted & $\begin{array}{l}1.5-3 \mathrm{~h} \text {, longer with } \\
\text { alcohol }\end{array}$ \\
\hline $\begin{array}{l}\text { d-lysergic acid } \\
\text { diethylamide (LSD) }\end{array}$ & Acid, Trips (high form), Acid Blotter, Dots, Boomers, Yellow sunshine & Oral & $8-12 \mathrm{~h}$ \\
\hline Ketamine & K, Special K, Super K, Ketalar, Green & $\begin{array}{l}\text { Intranasal, by injection, } \\
\text { oral }\end{array}$ & $1-2 \mathrm{~h}$ \\
\hline Benzodiazepines & Candy, Tranks, Downers, Sleeping pills, Xanax, Ativan, Valium & Oral & $\begin{array}{l}\text { Last up to } 24 \mathrm{~h} \text { if long- } \\
\text { acting }\end{array}$ \\
\hline
\end{tabular}

\section{TABLE 2: Common street names for substances and routes of administration}

MDMA (3,4-Methylenedioxymethamphetamine), PMA (Paramethoxyamphetamine)

Adolescents are more vulnerable to use multiple substances to achieve their "high" compared to adults. Recognition of specific group/ toxidromes will facilitate the management, even when the specific substance is unknown. Table 3 summarises the physical finding of different substances $[4,6]$. 


\section{Cureus}

\begin{tabular}{|c|c|c|c|c|}
\hline & Respiratory & Cardiovascular/Autonomic & Central Nervous System (CNS) & Gastrointestinal \\
\hline Cannabis & $\begin{array}{l}\text { Frequent } \\
\text { respiratory } \\
\text { infections, cough }\end{array}$ & $\begin{array}{l}\text { Tachycardia, sweating, tremors, high fever, } \\
\text { chills }\end{array}$ & $\begin{array}{l}\text { Psychological disturbance: } \\
\text { depersonalisation, decreased } \\
\text { inhibition, disorientation, altered } \\
\text { mood, lack of attention, memory } \\
\text { impairment }\end{array}$ & $\begin{array}{l}\text { Abdominal pain, } \\
\text { hyperemesis } \\
\text { syndrome }\end{array}$ \\
\hline $\begin{array}{l}\text { morphine, } \\
\text { codeine, } \\
\text { oxycodone, and } \\
\text { fentanyl) }\end{array}$ & $\begin{array}{l}\text { Respiratory } \\
\text { depression, } \\
\text { pulmonary } \\
\text { oedema }\end{array}$ & $\begin{array}{l}\text { Autonomic effects: miosis sweating, } \\
\text { hypothermia Cardiovascular effects: } \\
\text { bradycardia, hypotension }\end{array}$ & CNS depression: drowsiness to coma & $\begin{array}{l}\text { Dry mouth, } \\
\text { nausea, } \\
\text { vomiting, } \\
\text { constipation }\end{array}$ \\
\hline $\begin{array}{l}\text { Stimulants } \\
\text { (cocaine, } \\
\text { amphetamine and } \\
\text { MDMA) }\end{array}$ & $\begin{array}{l}\text { Pulmonary } \\
\text { oedema, } \\
\text { respiratory } \\
\text { distress due to } \\
\text { pulmonary } \\
\text { barotrauma }\end{array}$ & $\begin{array}{l}\text { Autonomic effects: mydriasis, } \\
\text { hyperthermia, flushing, diaphoresis } \\
\text { Cardiovascular effects: hypertension, } \\
\text { tachycardia, arrhythmias myocardial } \\
\text { depression }\end{array}$ & $\begin{array}{l}\text { CNS excitation: agitation, euphoria, } \\
\text { delirium, hallucinations, psychosis, } \\
\text { seizures neuromuscular excitation: } \\
\text { hyper-reflexia, tremor }\end{array}$ & $\begin{array}{l}\text { Nausea, } \\
\text { stomach pain }\end{array}$ \\
\hline $\begin{array}{l}\text { Benzodiazepines } \\
\text { (lorazepam, } \\
\text { alprazolam, } \\
\text { diazepam, } \\
\text { clonazepam) }\end{array}$ & $\begin{array}{l}\text { Respiratory } \\
\text { depression }\end{array}$ & Hypotension, bradycardia & $\begin{array}{l}\text { CNS depression, slurred speech, } \\
\text { ataxia, drowsiness, confusion, } \\
\text { impaired judgment }\end{array}$ & \\
\hline $\begin{array}{l}\text { Gamma } \\
\text { hydroxybutyrate } \\
\text { (GHB) }\end{array}$ & $\begin{array}{l}\text { Rapid onset of } \\
\text { respiratory } \\
\text { depression }\end{array}$ & Miosis, hypothermia, bradycardia & $\begin{array}{l}\text { CNS depression, anterograde } \\
\text { amnesia, hallucinations, euphoria, } \\
\text { disinhibition, sociability }\end{array}$ & $\begin{array}{l}\text { Nausea, } \\
\text { vomiting, } \\
\text { abdominal pain }\end{array}$ \\
\hline $\begin{array}{l}\text { LSD (d-lysergic } \\
\text { acid diethylamide) }\end{array}$ & & $\begin{array}{l}\text { Autonomic effects: mydriasis, } \\
\text { hyperthermia, sweating cardiovascular } \\
\text { effects: tachycardia, hypertension, }\end{array}$ & $\begin{array}{l}\text { Delusion, hallucinations, impaired } \\
\text { motor coordination, perceptual } \\
\text { distortion, agitation }\end{array}$ & $\begin{array}{l}\text { Nausea, loss of } \\
\text { appetite }\end{array}$ \\
\hline Ketamine & $\begin{array}{l}\text { Difficulty in } \\
\text { breathing }\end{array}$ & Tachycardia, hypertension & $\begin{array}{l}\text { Impaired consciousness, euphoria, } \\
\text { altered perceptions, mystical } \\
\text { experiences }\end{array}$ & Abdominal pain \\
\hline
\end{tabular}

TABLE 3: Acute signs and symptoms of substance use in adolescents

MDMA (3,4-Methylenedioxymethamphetamine)

\section{Differential diagnosis}

There are a number of differential diagnoses for altered mental status or agitation, which need to be actively ruled out in those who present with suspicious substance intoxication. Hypoglycaemia is an easily reversible differential diagnosis. Meningitis and encephalitis need to be considered in those who present with a history of fever, headache, vomiting followed by altered mental status and nuchal rigidity. Sepsis has to be considered in systemically ill adolescents with foci of infection [7,8]. Headache, recent onset behavioural changes, focal neurological deficits and seizure can be the presentation of a space-occupying lesion.

Overdose of over-the-counter medications leading to anticholinergic toxidrome, salicylate overdose, and serotonin syndrome are also important differential diagnoses in adolescents with deliberate self-harm and substance use. Recent history of trauma/accidents warrants ruling out head injury. Heat exhaustion/heat stroke is another differential diagnosis that correlates with environmental temperature and outdoor prolonged sports/exercise [8]. Thyrotoxicosis and pheochromocytoma have to be considered in adolescents with suggestive systemic clinical features such as eye signs, paroxysmal headache, sweating and palpitation; however, they are uncommon. Psychosis/schizophrenia can be a diagnosis of exclusion and correlates with background and family history of psychiatric illness [9].

\section{Investigations}

Acute intoxication features may overlap with sepsis or encephalitis, which may warrant sepsis work up such as full blood count, C-reactive protein (CRP) and cultures based on the focus of infection. Blood sugar should be determined to exclude hypoglycaemia. Urine human chorionic gonadotropin (HCG) should be done 
in all adolescent females to exclude unintended pregnancy. Blood gas assessment is helpful in identifying metabolic and respiratory acidosis and oxygenation. Creatine kinase is performed in patients with delirium or aggressive behaviour, hyperthermia and seizures to identify rhabdomyolysis. In substance abuse, electrocardiography (ECG) is essential in the detection of acute coronary syndrome and arrhythmias. It also helps to identify various changes due to electrolyte disturbances. A chest x-ray may be indicated in those with pulmonary barotrauma (spasmodic coughing following smoke inhalation), pneumonia, or pulmonary oedema $[3,8]$.

Blood alcohol level, blood paracetamol and salicylate levels are warranted in suspected co-ingestions. Drug testing has limited value in the diagnosis of substance abuse and they often do not quantify the severity of ingestions. Further, a negative drug value does not exclude the presence of substance use, especially with newer substances [3].

\section{Management in the acute setting}

Intoxicated patients should be assessed through the ABCDE approach. Early resuscitation is a life-saving measure in intoxicated patients. The management of substance overdose primarily involves supportive care $[10,11]$.

Airway and antidotes: CNS depression, altered level of consciousness, and hypersecretion lead to a threatened airway. Ensure the airway patency, which may necessitate intubation. Consider emergency empiric administration of antidotes following the establishment of the secured airway.

Breathing: Facilitate breathing with supplemental oxygen. Monitor oxygen saturation during management. Ventilator support is needed in lethal intoxication.

Circulation: Initiate cardiac monitoring and electrocardiographic studies. Intravenous access should be secured to ensure fluid administration. Adequate hydration is essential in intoxication.

Disability: Manage the patient in a calm environment. Verbal de-escalation is an important initial management step of agitation. If a poor response or aggressive behaviour, pharmacological management should be considered including the use of benzodiazepines. Exclude hypoglycaemia, which is a rapidly reversible cause of the agitation. Seizures should be actively managed with benzodiazepine [12]. Treat cardiac dysrhythmias and metabolic abnormalities.

Exposure: Manage hyperthermia by effectively cooling measures. Treat concomitant injuries.

Following initial stabilization, it is important to obtain a rapid history and thorough physical examination to look for an underlying toxic syndrome. This assessment will help in the early administration of decontamination and specific treatment.

\section{Management of specific substances}

Cannabis

The main clinical manifestations of cannabis intoxication are panic attacks, anxiety and autonomic instability. Acute toxicity is rarely serious and the main-stay of management is reassurance and supportive management. Benzodiazepines may be helpful to control agitation $[3,9]$.

Opioids

The main clinical features of opiate overdose include respiratory depression, miosis, bradycardia and stupor or coma. They may present with complications such as pulmonary oedema and aspiration pneumonitis. Determination of PCO2 level by blood gases is an assessment modality for hypoventilation. In mild to moderate cases, specific treatment is usually not necessary. The priority of management is the protection of the airway and giving ventilatory support. Naloxone, an opioid antagonist, is the antidote for opioid intoxication and should be titrated according to respiratory effort and rate. If long-acting opiate has been ingested, the patient may need IV naloxone infusion (rate set as $60 \%$ of initial bolus) as well as the prolonged observation $[6,9]$. The half-life of naloxone is shorter than opioids and this may lead to rebound opioid toxicity. Therefore, cardio-respiratory monitoring is crucial following initial stabilisation.

Stimulants: Amphetamines, Cocaine and MDMA

Sympathomimetic excess is characterized by autonomic and cardiovascular hyper-stimulation with neuropsychiatric clinical features such as agitation, delirium and hallucinations. The primary focus is calming the patient to prevent harm to the patient as well as to staff. Therefore, they have to be managed in a calm and low stimulant environment. Monitoring of vital signs including respiratory rate, heart rate, blood pressure and temperature is crucial in management. Benzodiazepines are the first-line medication for 
agitation or aggressive behaviour. Neuroleptics can be used if delusions or hallucinations are present. Hyperthermia can be fatal and should be treated actively. Institution of aggressive cooling measures and reduction of activity with benzodiazepines (even consider paralysis) are treatment measures for hyperthermia $[7,8]$.

Severe hypertension can cause cardiovascular and cerebrovascular complications. High blood pressure should be controlled with rapidly acting antihypertensive medications such as sodium nitroprusside (vasodilator) and phentolamine (alpha-adrenergic blocker) $[8,13]$. Chest pain warrants assessment for possible myocardial ischemia or infarction. The stimulant-induced acute coronary syndrome should be managed with nitrates, benzodiazepines, opiates and aspirin initially. If ischemia persists, it warrants standard therapy. Wide-complex tachyarrhythmias can be associated with cocaine overdose due to sodium channel blockade, and sodium bicarbonate is the treatment option [13].

Benzodiazepines

Respiratory depression and mental depression are the main clinical features of benzodiazepine overdose. The mainstay of management for acute intoxication is supportive care. Monitoring of vital signs including respiratory rate, oxygen saturation, level of consciousness and blood gas is essential in management. Acute management consists of maintaining the airway, facilitating ventilation with oxygenation and haemodynamic support. Flumazenil, a benzodiazepine antagonist, can be used in severe intoxication associated with respiratory and neurological depression [14]. If there is no reversal within 5-10 minutes of use of flumazenil, other diagnoses should be considered.

Other Substances

Consumption of newer drugs, such as gamma hydroxybutyrate (GHB), Ketamine and lysergic acid diethylamide (LSD), is mainly observed in club environments. Most of the drugs are consumed with other substances, especially alcohol. Mostly, new substance consumptions are misdiagnosed due to non-specific features and clinical features similar to other toxidromes including GHB intoxication, and intoxication of benzodiazepines, and barbiturates [15].

GHB is a short-acting clear liquid that causes CNS depression. The clinical features are similar to sedativehypnotic drugs overdose. Management is mainly supportive care; intubation might be needed to maintain airway patency and protect from aspiration [16]. LSD is a prominent hallucinogenic drug. Management of LSD intoxication is mainly supportive. Agitation and psychosis associated with LSD intoxication may need benzodiazepines [17].

\section{Complications}

Acute intoxication or repeated use of substances can cause multiple complications. Acute intoxication causes damage to multiple systems including the cardiovascular, respiratory, cerebrovascular and renal systems. Complications mainly depend on the type of substance, ingested dose, route of administration, and associated comorbidities and risky behaviour under the influence of the substance. Stimulant abuse leads to cardiovascular and cerebrovascular complications due to catecholamine excess. In the cardiovascular system, it causes arrhythmias, myocardial ischemia or infarction and cardiomyopathy. Especially cocaine is linked with wide complex tachyarrhythmias due to sodium channel blockade [7]. Cerebrovascular complications such as seizures, ischemic strokes and subarachnoid or intracerebral haemorrhages can occur due to direct cerebrovascular involvement [8].

Respiratory complications due to substance intoxication include pulmonary haemorrhage, pneumonia, pulmonary oedema, pneumothorax, pneumomediastinum, aspiration pneumonitis and respiratory arrest [11]. Further, bronchospasm is another frequent clinical presentation in smokers. Pulmonary barotrauma may be a consequence of spasmodic coughing with a sudden increase in airway pressure following smoke inhalation [13]. "Crack lung” is an acute pulmonary syndrome associated with smoking crack cocaine and leads to diffuse alveolar damage and haemorrhagic alveolitis within $48 \mathrm{~h}$ of smoking [18].

Delirium, seizure and hyperthermia can cause rhabdomyolysis leading to acute kidney injury. Infections are another entity of complications that arise due to parenteral use of substances or disinhibition causing participation in high risk or unprotected sexual activity. Parenteral use of substances causes blood-borne transmission of hepatitis B, C, and D and HIV/AIDS. Intravenous cocaine users are at high risk of infective endocarditis than other parenteral drug users [13]. Failure to intervene at an early stage to prevent substance consumption in adolescence often leads to substance addiction and dependence.

\section{Follow up beyond the emergency setting}

Adolescents with substance abuse should be collaboratively managed by primary care physicians and psychiatrists, beyond emergency care. Effective management should address holistic management of the patients and not just their substance use. Most of these adolescents have underlying psychiatric conditions, 
which have to be considered in their management [9]. Therefore, proper psychiatric care is essential for successful long-term management. Depending on the severity of the substance abuse disorder, treatment and follow up should be arranged at the appropriate level of care. This may include mental health counselling or specialized treatment programs in inpatient drug rehabilitation facilities [19].

\section{Conclusions}

Adolescent substance use is an emerging burden on the healthcare system. Effective management of acute substance intoxication requires accurate risk assessment, understanding of the pharmacological properties of the substance, and appropriate supportive care. Education of the adolescent patients and their family members on the immediate effects and long-term consequences of substance use including psychosocial and medical impact is essential in management. A collaborative team approach with family, primary care physicians and mental health providers is a key factor in the effective management of adolescents with substance abuse.

\section{Additional Information \\ Disclosures}

Conflicts of interest: In compliance with the ICMJE uniform disclosure form, all authors declare the following: Payment/services info: All authors have declared that no financial support was received from any organization for the submitted work. Financial relationships: All authors have declared that they have no financial relationships at present or within the previous three years with any organizations that might have an interest in the submitted work. Other relationships: All authors have declared that there are no other relationships or activities that could appear to have influenced the submitted work.

\section{References}

1. Senanayake S, Gunwardena S, Kumbukage M, et al.: Smoking, alcohol consumption, and illegal substance abuse among adolescents in Sri Lanka: results from Sri Lankan Global School-Based Health Survey 2016. Adv Public Health. 2018, 2018:9724176. 10.1155/2018/9724176

2. Preyde M, Furtado J, Head S, et al.: Foundations of addictive problems in adolescents: Developmental and social factors. Adolescent Addiction (Second Edition). Cecilia A (ed): Academic Press, London; 2020. 3-17. 10.1016/B978-0-12-818626-8.00001-3

3. Li W, Gunja N: Illicit drug overdose--prevalence and acute management . Aust Fam Physician. 2013, 42:4815 .

4. Leslie K: Youth substance use and abuse: challenges and strategies for identification and intervention . CMAJ. 2008, 178:145-8. 10.1503/cmaj.071410

5. Ramo D, Grov C: Other Illicit Drugs of Abuse in Adolescence. Robert A, Zucker RA, Brown SA (ed): Oxford University Press, New York, NY; 2019. 10.1093/oxfordhb/9780199735662.013.009

6. Maviglia MA: Alcohol and drug abuse intervention in the emergency department. Psychiatric Times. 2006, 23:1.

7. van Loggerenberg CJ: Management of stimulant drug overdose. CME. 2007, 25:128-33.

8. Methamphetamine in the ED Setting. (2020). Accessed: June 8, 2021: http://www.emdocs.net/methamphetamine-in-the-ed-setting/.

9. Amaral RA, Malbergier A, Andrade AG: Management of patients with substance use illnesses in psychiatric emergency department (Article in Portuguese). Braz J Psychiatry. 2010, 32 Suppl 2:S104-11. 10.1590/s151644462010000600007

10. Treatment approaches for drug addiction. (2019). Accessed: June 8, 2021: https://www.drugabuse.gov/publications/drugfacts/treatment-approaches-drug-addiction.

11. Maldonado JR: An approach to the patient with substance use and abuse . Med Clin North Am. 2010, 94:1169-205. 10.1016/j.mcna.2010.08.010

12. Shapiro B, Coffa D, McCance-Katz EF: A primary care approach to substance misuse. Am Fam Physician. 2013, 15:113-21.

13. Center for Substance Abuse Treatment: Treatment for Stimulant Use Disorders . Substance Abuse and Mental Health Services Administration, Rockville, MD; 1999.

14. An H, Godwin J: Flumazenil in benzodiazepine overdose. CMAJ. 2016, 188:E537. 10.1503/cmaj.160357

15. Winstock AR, Mitcheson L: New recreational drugs and the primary care approach to patients who use them BMJ. 2012, 344:e288. 10.1136/bmj.e288

16. Busardò FP, Jones AW: GHB pharmacology and toxicology: acute intoxication, concentrations in blood and urine in forensic cases and treatment of the withdrawal syndrome. Curr Neuropharmacol. 2015, 13:47-70. 10.2174/1570159X13666141210215423

17. Wilson MP, Pepper D, Currier GW, Holloman GH Jr, Feifel D: The psychopharmacology of agitation: consensus statement of the American Association for Emergency Psychiatry Project Beta Psychopharmacology Workgroup. West J Emerg Med. 2012, 13:26-34. 10.5811/westjem.2011.9.6866

18. Giacomi FD, Srivali N: Cocaine use and crack lung syndrome. QJM. 2019, 112:125-6. 10.1093/qjmed/hcy255

19. Onigu-Otite E, Kurtzweil M, Tucci V, Moukaddam N: Substance use in adolescents presenting to the emergency department. Adolesc Psychiatry. 2019, 9:142-58. 10.2174/2210676608666181015114220 